Author affiliations and support information (if applicable) appear at the end of this article.

Published at jco.org on May 1, 2017.

Corresponding author: Lillian Sung, MD, $\mathrm{PhD}$, Division of Haematology/Oncology, The Hospital for Sick Children, 555 University Ave, Toronto, Ontario, Canada M5G 1X8; e-mail: lillian.sung@sickkids.ca.

(C) 2017 by American Society of Clinical Oncology

$0732-183 X / 17 / 3518 w-2082 w / \$ 20.00$

\title{
Guideline for the Management of Fever and Neutropenia in Children With Cancer and Hematopoietic Stem-Cell Transplantation Recipients: 2017 Update
}

Thomas Lehrnbecher, Paula Robinson, Brian Fisher, Sarah Alexander, Roland A. Ammann, Melissa Beauchemin, Fabianne Carlesse, Andreas H. Groll, Gabrielle M. Haeusler, Maria Santolaya, William J. Steinbach, Elio Castagnola, Bonnie L. Davis, L. Lee Dupuis, Aditya H. Gaur, Wim J.E. Tissing, Theo Zaoutis, Robert Phillips, and Lillian Sung

\section{$\begin{array}{llllllll}\text { A } & B & \mathbf{S} & \mathbf{T} & \mathbf{R} & \mathbf{A} & \mathbf{C} & \mathbf{T}\end{array}$}

\section{Purpose}

To update a clinical practice guideline (CPG) for the empirical management of fever and neutropenia (FN) in children with cancer and hematopoietic stem-cell transplantation recipients.

\section{Methods}

The International Pediatric Fever and Neutropenia Guideline Panel is a multidisciplinary and multinational group of experts in pediatric oncology and infectious diseases that includes a patient advocate. For questions of risk stratification and evaluation, we updated systematic reviews of observational studies. For questions of therapy, we conducted a systematic review of randomized trials of any intervention applied for the empirical management of pediatric FN. The Grading of Recommendation Assessment, Development and Evaluation approach was used to make strong or weak recommendations and to classify levels of evidence as high, moderate, low, or very low.

\section{Results}

Recommendations related to initial presentation, ongoing management, and empirical antifungal therapy of pediatric FN were reviewed; the most substantial changes were related to empirical antifungal therapy. Key differences from our 2012 FN CPG included the listing of a fourth-generation cephalosporin for empirical therapy in high-risk FN, refinement of risk stratification to define patients with high-risk invasive fungal disease (IFD), changes in recommended biomarkers and radiologic investigations for the evaluation of IFD in prolonged FN, and a weak recommendation to withhold empirical antifungal therapy in IFD low-risk patients with prolonged FN.

\section{Conclusion}

Changes to the updated FN CPG recommendations will likely influence the care of pediatric patients with cancer and those undergoing hematopoietic stem-cell transplantation. Future work should focus on closing research gaps and on identifying ways to facilitate implementation and adaptation.

\section{J Clin Oncol 35:2082-2094. (C) 2017 by American Society of Clinical Oncology}

\section{INTRODUCTION}

Fever and neutropenia (FN) is a common complication of cancer treatment. In 2012, we published a clinical practice guideline (CPG) focused on the management of FN in children with cancer and in recipients of hematopoietic stem-cell transplantation (HSCT). ${ }^{1}$ Like all CPGs, it is important that the systematic reviews that inform the recommendations are timely, typically considered every 5 years in the absence of important new studies. Consequently, we updated the systematic reviews and present the 2017 pediatric FN CPG.

\section{METHODS}

The International Pediatric Fever and Neutropenia Guideline Panel includes representation from pediatric oncology, infectious diseases, nursing, and pharmacy, as well as a patient advocate and a guideline methodologist from 10 different countries (Data Supplement).

The methodology applied to our CPG update mirrored our 2012 FN CPG. We followed previously validated procedures for creating evidence-based 
guidelines ${ }^{2}$ and used the Appraisal of Guidelines for Research \& Evaluation II instrument as a framework. ${ }^{3}$ Each member completed a conflict of interest form (Data Supplement). The funding agencies had no role to play in the recommendations or editing of the manuscript. The Grading of Recommendation Assessment, Development and Evaluation approach was used to generate recommendations. Details of methodology may be found in the Data Supplement.

Members were divided into working groups that focused on the three major sections addressed in the initial CPG: initial presentation, ongoing management, and empirical antifungal therapy. Given the paucity of pediatric data at the time of initial CPG development, none of the original systematic reviews were restricted to randomized controlled trials (RCTs). For the guideline update, we decided to focus on pediatric RCTs for questions related to therapy because we believed that clinical practice was unlikely to change on the basis of additional observational studies alone. For questions related to risk stratification and evaluation, the original systematic reviews were updated. The Data Supplement contains details of the search strategies, flow diagrams of study identification and selection, and eligibility criteria.

\section{RECOMMENDATIONS AND EXPLANATIONS}

Table 1 presents the 2017 recommendations, highlights changes from the 2012 FN CPG, and provides key remarks. The associated evidence profiles are illustrated in the Data Supplement when data were not published in separate manuscripts. Research gaps are presented in Table 2.

\section{SECTION A: INITIAL PRESENTATION OF FN}

\section{Question}

What clinical features and laboratory markers can be used to classify pediatric patients with $\mathrm{FN}$ as being at low risk or high risk of poor outcomes?

\section{Recommendation}

A1. Adopt a validated risk stratification strategy (Table 3 ) and incorporate it into routine clinical management (strong recommendation, low-quality evidence).

Literature update and analysis. The 2012 recommendation was derived from a systematic review ${ }^{16}$ that demonstrated a number of schemas that varied by patients included, definitions of $\mathrm{FN}$, and outcomes measured. Updating the systematic review (Data Supplement) demonstrated further validation of previously published schemas, and more small studies deriving new rules. Six clinically based low-risk stratification schemas that rely on a single assessment at presentation have been validated in different pediatric populations (Table 3). Even with further information, we remain unable to clearly recommend any single prediction rule. There remains evidence of geographical and temporal variation; thus, all schemas require local validation before use. The choice of strategy should be determined by an institution's ability to implement more complex rules and the timeliness of receipt of required components of the rule, such as C-reactive protein. Two additional risk stratification schemas including repeated measurement of biomarkers have been derived and successfully validated in their originating groups. ${ }^{17,18}$ These use clinical assessment and IL-8 measurements for all pediatric patients ${ }^{17}$ or IL8 and C-reactive protein for a high-risk group. ${ }^{18}$

\section{Question}

What clinical, laboratory, and imaging studies are useful at the initial presentation of FN to assess the cause of the episode and guide future treatment?

\section{Recommendations}

A2. Obtain blood cultures at the onset of FN from all lumens of central venous catheters (strong recommendation, lowquality evidence).

A3. Consider obtaining peripheral blood cultures concurrent with central venous catheter cultures (weak recommendation, moderate-quality evidence).

A4. Consider urinalysis and urine culture in patients in whom a clean-catch, midstream specimen is readily available (weak recommendation, low-quality evidence).

A5. Obtain chest radiography (CXR) only in patients with respiratory signs or symptoms (strong recommendation, moderate-quality evidence).

Literature update and analysis. The value of peripheral blood cultures has been addressed in nine studies, ${ }^{19-27}$ two of which were published after 2011. ${ }^{19,20}$ The updated estimate of the proportion of true bacteremia episodes detected by peripheral blood cultures alone, when central venous catheter cultures are negative, was 12\% (95\% CI, $8 \%-17 \%)$. Thus, peripheral cultures consistently increase the identification of true bacteremia compared with central cultures alone, which may be related to timing or volume. It is a weak recommendation because the impact of increased yield is unknown and it should be balanced against pain and isolation of contaminants.

In terms of urinalysis and urine culture to detect urinary tract infections in pediatric $\mathrm{FN}$, in one study, all patients with positive urine cultures were asymptomatic, ${ }^{28}$ strengthening the conclusion that restricting urine culture to those with symptoms is not adequate. The use of abnormal urinalysis to triage culture is also not recommended because pyuria was present in only $4 \%$ of urinary tract infection episodes during neutropenia ${ }^{29}$ and nitrite testing in younger children (without cancer) is less discriminatory than in older patients. ${ }^{30}$

Two additional studies have been added to the initial systematic review ${ }^{16}$ of the use of routine CXR during the initial assessment of pediatric FN. One was undertaken in a broad cohort of patients with $\mathrm{FN}^{31}$ and one in children undergoing HSCT. ${ }^{32}$ Both demonstrated rates of pneumonia of $<3 \%$ in an asymptomatic child. Asymptomatic children who did not undergo CXR had no significant adverse clinical consequences. ${ }^{33}$ Thus, no change was made to the strong recommendation to obtain CXR only in patients with respiratory signs or symptoms.

\section{Question}

What empirical antibiotics are appropriate for children with high-risk FN?

\section{Recommendations}

A6. In high-risk FN:

A6a. Use monotherapy with an antipseudomonal $\beta$-lactam, a fourth-generation cephalosporin, or a carbapenem as empirical therapy in pediatric high-risk FN (strong recommendation, high-quality evidence).

A6b. Reserve the addition of a second gram-negative agent or a glycopeptide for patients who are clinically unstable, when a resistant infection is suspected, or for centers with a high rate of resistant pathogens (strong recommendation, moderate-quality evidence).

Literature update and analysis. In the systematic review of RCTs of pediatric FN, we compared monotherapy with 
aminoglycoside-containing combination therapy, and the results are presented in Table $4 .{ }^{34}$ In this comparison, a rate ratio $>1$ indicates that monotherapy is better than combination therapy. No significant differences in failure rates, infection-related mortality, or overall mortality were observed. Three studies were conducted solely in patients with high-risk $\mathrm{FN}^{35-37}$ and among these studies, no difference in treatment failure was observed (rate ratio, 1.14 ; 95\% CI, 0.54 to 2.39; $P=.73)$. However, it is important to note that these three RCTs did not evaluate monotherapy with a $\beta$-lactam against the same $\beta$-lactam plus an aminoglycoside, thus highlighting the importance of the specific monotherapy $\beta$-lactam antibiotic used. This analysis confirmed the efficacy and safety of monotherapy without the addition of aminoglycosides in treatment settings in which resistance rates were low enough to permit random assignment between monotherapy and combination therapy. Consequently, the updated CPG continues to have a strong recommendation to use empirical monotherapy in high-risk FN.

Table 1. Overall Summary of Recommendations, Changes, and Remarks

\begin{tabular}{|c|c|c|}
\hline Recommendation & Change From Previous Guideline & Remarks \\
\hline \multicolumn{3}{|l|}{$\begin{array}{l}\text { Initial management } \\
\text { Risk stratification }\end{array}$} \\
\hline $\begin{array}{l}\text { A1. Adopt a validated risk stratification strategy } \\
\text { and incorporate it into routine clinical } \\
\text { management (strong recommendation, } \\
\text { low-quality evidence). }\end{array}$ & None & $\begin{array}{l}\text { Strategy choice should be determined by } \\
\text { validation in a similar context, and ability to } \\
\text { implement based on complexity and } \\
\text { availability of required components such as } \\
\text { biomarkers. }\end{array}$ \\
\hline
\end{tabular}

A2. Obtain blood cultures at the onset of FN None

from all lumens of central venous catheters (strong recommendation, low-quality evidence).

A3. Consider obtaining peripheral blood cultures concurrent with central venous catheter cultures (weak recommendation, moderate-quality evidence).

A4. Consider urinalysis and urine culture in patients in whom a clean-catch, midstream specimen is readily available (weak recommendation, low-quality evidence).

A5. Obtain chest radiography only in patients with respiratory signs or symptoms (strong recommendation, moderateTreatment quality evidence)

A6. In high-risk FN:

A6a. Use monotherapy with an antipseudomonal $\beta$-lactam, a fourthgeneration cephalosporin, or a carbapenem as empirical therapy in pediatric high-risk FN (strong recommendation, high-quality evidence).

A6b. Reserve addition of a second gramnegative agent or a glycopeptide for patients who are clinically unstable. when a resistant infection is suspected, or for centers with a high rate of resistant pathogens (strong recommendation, moderate-quality evidence).

A7. In low-risk FN:

A7a. Consider initial or step-down outpatient management if the infrastructure is in place to ensure careful monitoring and follow-up (weak recommendation, moderate-quality evidence).

A7b. Consider oral antibiotic administration if the child is able to tolerate this route of administration reliably (weak recommendation, moderate-quality evidence).

None

Quality of evidence increased to moderate from low

None

Fourth-generation cephalosporin added

None

None

None
Peripheral cultures consistently increase identification of true bacteremia compared with central cultures alone. It is a weak recommendation because the impact of increased yield is unknown and should be balanced against pain and isolation of contaminants.

Antibiotics should not be delayed to obtain urine specimen.
The Panel valued the consistency of data suggesting efficacy and safety of monotherapy in pediatric randomized trials. Monotherapy may not be appropriate for centers with a high rate of resistance, or for patients who present with hemodynamic instability.

Threshold for when rates of resistance are sufficiently high to support empirical combination or glycopeptide therapy has not been established and will vary by institution depending on preferences and available alternatives.

It is a weak recommendation because institutions must have the infrastructure in place to safely implement outpatient management. Clinical outcomes were similar between strategies and thus, resources and preferences are important considerations.

It is a weak recommendation because readmission may be higher among outpatients treated with oral $v$ parenteral therapy, and other outcomes were similar. Thus, resources and preferences are important considerations. 
Table 1. Overall Summary of Recommendations, Changes, and Remarks (continued)

\begin{tabular}{|c|c|c|}
\hline Recommendation & Change From Previous Guideline & Remarks \\
\hline \multicolumn{3}{|l|}{ Ongoing management } \\
\hline \multicolumn{3}{|l|}{ Modification of treatment } \\
\hline $\begin{array}{l}\text { B1. In patients who are responding to initial } \\
\text { empirical antibiotic therapy, discontinue } \\
\text { double coverage for gram-negative } \\
\text { infection or empirical glycopeptide (if } \\
\text { initiated) after } 24 \text { to } 72 \text { hours if there is no } \\
\text { specific microbiologic indication to } \\
\text { continue combination therapy (strong } \\
\text { recommendation, moderate-quality } \\
\text { evidence). }\end{array}$ & None & $\begin{array}{l}\text { Rationale is same as that for the } \\
\text { recommendation for initial empirical } \\
\text { monotherapy. The Panel valued reducing } \\
\text { unnecessary antibiotic administration to } \\
\text { reduce toxicity, costs, and antibiotic } \\
\text { resistance. }\end{array}$ \\
\hline $\begin{array}{l}\text { B2. Do not modify the initial empirical } \\
\text { antibacterial regimen based solely on } \\
\text { persistent fever in children who are } \\
\text { clinically stable (strong recommendation, } \\
\text { low-quality evidence). }\end{array}$ & None & \\
\hline $\begin{array}{l}\text { B3. In children with persistent fever who } \\
\text { become clinically unstable, escalate the } \\
\text { initial empirical antibacterial regimen to } \\
\text { include coverage for resistant gram- } \\
\text { negative, gram-positive, and anaerobic } \\
\text { bacteria (strong recommendation, very } \\
\text { low-quality evidence). }\end{array}$ & None & \\
\hline \multicolumn{3}{|l|}{ Cessation of treatment } \\
\hline $\begin{array}{l}\text { B4. In all patients, discontinue empirical } \\
\text { antibiotics in patients who have negative } \\
\text { blood cultures at } 48 \text { hours, who have been } \\
\text { afebrile for at least } 24 \text { hours, and who have } \\
\text { evidence of marrow recovery (strong } \\
\text { recommendation, low-quality evidence). }\end{array}$ & None & $\begin{array}{l}\text { A specific threshold to define count recovery } \\
\text { has not been established. }\end{array}$ \\
\hline $\begin{array}{l}\text { B5. In patients with low-risk FN, consider } \\
\text { discontinuation of empirical antibiotics at } \\
72 \text { hours in patients who have negative } \\
\text { blood cultures and who have been afebrile } \\
\text { for at least } 24 \text { hours, irrespective of } \\
\text { marrow recovery status, as long as careful } \\
\text { follow-up is ensured (weak } \\
\text { recommendation, moderate-quality } \\
\text { evidence). }\end{array}$ & None & $\begin{array}{l}\text { Although safety of early discontinuation of } \\
\text { empirical antibiotics in low-risk FN has been } \\
\text { examined, the specific question of early } \\
\text { discontinuation in the setting of no bone } \\
\text { marrow recovery has not been directly } \\
\text { addressed, thus leading to the weak } \\
\text { recommendation. }\end{array}$ \\
\hline \multicolumn{3}{|l|}{ Empirical antifungal therapy } \\
\hline \multicolumn{3}{|l|}{ Risk stratification } \\
\hline $\begin{array}{l}\text { C1. Patients at high risk of IFD are those with } \\
\text { AML, high-risk ALL, or relapsed acute } \\
\text { leukemia, and children undergoing } \\
\text { allogeneic HSCT. Children with prolonged } \\
\text { neutropenia and children receiving high- } \\
\text { dose corticosteroids are also at high risk of } \\
\text { IFD. All others should be categorized as } \\
\text { IFD low risk (strong recommendation, } \\
\text { low-quality evidence). }\end{array}$ & $\begin{array}{l}\text { Risk factors refined. Quality of evidence } \\
\text { decreased to low from moderate }\end{array}$ & $\begin{array}{l}\text { Risk stratification rules are not yet available for } \\
\text { prediction of IFD. The Panel recognized that } \\
\text { high-risk ALL is a heterogeneous group and } \\
\text { this risk may be explained by prolonged } \\
\text { neutropenia and corticosteroid } \\
\text { administration. However, data to provide } \\
\text { further specification around which patient } \\
\text { with ALL is at particular risk of IFD and } \\
\text { treatment periods of IFD risk are not } \\
\text { available. }\end{array}$ \\
\hline \multicolumn{3}{|l|}{ Evaluation } \\
\hline \multicolumn{3}{|l|}{$\begin{array}{l}\text { C2. In terms of biomarkers to guide empirical } \\
\text { antifungal management for prolonged } \\
\text { ( } \geq 96 \text { hours) FN in IFD high-risk patients: }\end{array}$} \\
\hline $\begin{array}{l}\text { C2a. Consider not using serum GM (weak } \\
\text { recommendation, moderate-quality } \\
\text { evidence). }\end{array}$ & $\begin{array}{l}\text { Previously had been weak recommendation for } \\
\text { GM for surveillance and during FN. Now weak } \\
\text { recommendation against GM and restricted } \\
\text { recommendation to prolonged FN }\end{array}$ & $\begin{array}{l}\text { The Panel deliberated over how GM results } \\
\text { would be used clinically and the impact of } \\
\text { poor positive predictive values in the setting } \\
\text { of typical IFD rates. Poor positive predictive } \\
\text { values mean that actions based on test } \\
\text { results are often incorrect. High negative } \\
\text { predictive values are less useful because } \\
\text { GM does not rule out non-Aspergillus molds. }\end{array}$ \\
\hline $\begin{array}{l}\text { C2b. Do not use } \beta \text {-D-glucan. Strong } \\
\text { recommendation, low-quality evidence }\end{array}$ & None & $\begin{array}{l}\text { Poor positive predictive values and limited data } \\
\text { in prolonged FN setting }\end{array}$ \\
\hline $\begin{array}{l}\text { C2c. Do not use fungal PCR testing in blood } \\
\text { (strong recommendation, moderate- } \\
\text { quality evidence). }\end{array}$ & New recommendation & $\begin{array}{l}\text { Poor positive predictive values. Negative } \\
\text { predictive values not sufficiently high to be } \\
\text { clinically useful. PCR testing not yet } \\
\text { standardized. }\end{array}$ \\
\hline \multicolumn{3}{|c|}{ (continued on following page) } \\
\hline
\end{tabular}


Table 1. Overall Summary of Recommendations, Changes, and Remarks (continued)

\begin{tabular}{|c|c|c|}
\hline Recommendation & Change From Previous Guideline & Remarks \\
\hline \multicolumn{3}{|l|}{$\begin{array}{l}\text { C3. In terms of imaging for the evaluation of } \\
\text { prolonged ( } \geq 96 \text { hours) FN in IFD high-risk } \\
\text { patients: }\end{array}$} \\
\hline $\begin{array}{l}\text { C3a. Perform CT of the lungs (strong } \\
\text { recommendation, low-quality evidence). }\end{array}$ & $\begin{array}{l}\text { Quality of evidence decreased to low from } \\
\text { moderate }\end{array}$ & $\begin{array}{l}\text { Lungs consistently the most commonly } \\
\text { affected site. Optimal timing of initial and } \\
\text { repeated imaging not known. }\end{array}$ \\
\hline $\begin{array}{l}\text { C3b. Consider imaging of abdomen in patients } \\
\text { without localizing signs or symptoms } \\
\text { (weak recommendation, low-quality } \\
\text { evidence). }\end{array}$ & New recommendation & $\begin{array}{l}\text { Ideal imaging modality not known, but } \\
\text { ultrasound is readily available, is not } \\
\text { associated with radiation exposure, usually } \\
\text { does not require sedation, and thus is likely } \\
\text { preferable over CT or MRI. }\end{array}$ \\
\hline $\begin{array}{l}\text { C3c. Consider not routinely performing CT of } \\
\text { sinuses in patients without localizing } \\
\text { signs or symptoms (weak } \\
\text { recommendation, low-quality evidence). }\end{array}$ & $\begin{array}{l}\text { Previously had been weak recommendation for } \\
\text { CT sinuses. Now weak recommendation } \\
\text { against CT sinuses }\end{array}$ & $\begin{array}{l}\text { Sinus imaging is frequently abnormal in } \\
\text { prolonged FN, and abnormalities do not } \\
\text { seem to distinguish between those with and } \\
\text { without sinus IFD. It is a weak } \\
\text { recommendation because studies directly } \\
\text { addressing the usefulness of routine sinus } \\
\text { CTs are limited. }\end{array}$ \\
\hline \multicolumn{3}{|l|}{ Treatment } \\
\hline $\begin{array}{l}\text { C4. In IFD high-risk patients with prolonged } \\
\text { ( } \geq 96 \text { hours) FN unresponsive to broad- } \\
\text { spectrum antibacterial agents, initiate } \\
\text { caspofungin or liposomal amphotericin } \\
\text { B for empirical antifungal therapy (strong } \\
\text { recommendation, high-quality evidence). }\end{array}$ & None & \\
\hline $\begin{array}{l}\text { C5. In IFD low-risk patients with prolonged } \\
\text { ( } \geq 96 \text { hours) FN, consider withholding } \\
\text { empirical antifungal therapy (weak } \\
\text { recommendation, low-quality evidence). }\end{array}$ & $\begin{array}{l}\text { Previously had been weak recommendation for } \\
\text { empirical therapy for IFD low-risk patients. } \\
\text { Now weak recommendation against empirical } \\
\text { therapy for IFD low-risk patients }\end{array}$ & $\begin{array}{l}\text { Single randomized trial showed similar } \\
\text { outcomes with providing } v \text { withholding } \\
\text { empirical antifungal therapy for IFD low-risk } \\
\text { patients. However, the study was small and } \\
\text { thus considerable imprecision exists, } \\
\text { resulting in a weak recommendation. }\end{array}$ \\
\hline
\end{tabular}

Abbreviations: ALL, acute lymphoblastic leukemia; AML, acute myeloid leukemia; CT, computed tomography; FN, fever and neutropenia; GM, galactomannan; MRI, magnetic resonance imaging; PCR, polymerase chain reaction.

However, local epidemiology and resistance patterns should be evaluated regularly.

Table 4 also demonstrates the comparison between antipseudomonal penicillin monotherapy and fourth-generation cephalosporin monotherapy. ${ }^{38-42}$ Five studies were included; one study ${ }^{42}$ was identified in the updated search after publication of the FN systematic review. ${ }^{34}$ No differences in treatment failure, infectionrelated mortality, or duration of fever were observed, and the point estimate for mortality was in favor of the fourth-generation cephalosporin, thus arguing for its inclusion in the empirical antibiotic recommendation. The 0.81 day increase in duration of antibiotics associated with cephalosporin therapy was not considered clinically meaningful.

\section{Question}

In children with low-risk $\mathrm{FN}$, is initial or step-down outpatient management as effective and safe as inpatient management? Is initial or step-down oral antibiotic management as effective and safe as management with parenteral antibiotics?

\section{Recommendations}

A7. In low-risk FN:

A7a. Consider initial or step-down outpatient management if the infrastructure is in place to ensure careful monitoring and follow-up (weak recommendation, moderate-quality evidence).

A7b. Consider oral antibiotic administration if the child is able to tolerate this route of administration reliably (weak recommendation, moderate-quality evidence).
Literature update and analysis. In the systematic review of pediatric FN RCTs, treatment setting and route of antibiotic administration were examined ${ }^{34}$ (Table 4). Four studies randomized patients to inpatient versus outpatient therapy ${ }^{43-46}$; no differences in outcomes were observed. The point estimates favored outpatient management in the mortality analyses, and no infection-related deaths were reported for the 124 randomly assigned low-risk patients treated as outpatients. It is a weak recommendation because institutions must have the infrastructure in place to safely implement outpatient management. Because clinical outcomes were similar among strategies, resources and preferences are important considerations in strategy choice.

Table 4 also lists the comparison between intravenous and oral therapy among patients treated in the same setting $(\mathrm{n}=$ eight studies). ${ }^{47-54}$ There was no significant difference in treatment failure, and no infection-related mortality was reported among the 470 patients randomly assigned to receive oral empirical therapy. It is a weak recommendation because readmission may be higher among outpatients treated with oral versus parenteral therapy, and other outcomes were similar. Thus, resources and preferences are important considerations.

\section{SECTION B: ONGOING MANAGEMENT OF FN EXCLUDING EMPIRICAL THERAPY}

\section{Question}

When and how should the initial empirical antibiotic therapy be modified during the pediatric FN episode? 
Table 2. Research Gaps

Initial presentation

Optimal temperature threshold to define fever

New serum biomarkers as diagnostic and monitoring aids

Impact of viral diagnosis and the role of systemic viruses on

management of FN

Appropriate monitoring and follow-up for outpatient therapy

Optimal choice of empirical antibiotics in low-risk FN

Ongoing management

Timing and necessity of repeated blood cultures for persistent fever

Duration of empirical antibiotics for low- and high-risk FN

Role of providing targeted antibiotics only $v$ continuing broad-spectrum coverage in patients with positive cultures who remain neutropenic

Determining whether the diagnostic and therapeutic approach should differ between patients with prolonged continuous fever $v$ recurrent fever during FN

Empirical antifungal management

Role of combination biomarkers for IFD evaluation and ongoing management

Identifying novel biomarkers for IFD detection

Role and timing of standard imaging on patient outcomes

Efficacy and safety of pre-emptive antifungal therapy*

Appropriate duration of empirical antifungal therapy

Determining appropriate pediatric dosing for currently available antifungal

agents, and identifying novel antifungal agents for empirical therapy

Cost effectiveness of different approaches to manage pediatric $\mathrm{FN}$

Abbreviations: FN, fever and neutropenia; IFD, invasive fungal disease.

*Defined as initiating systemic antifungal therapy initiation only on clinical, radiologic, or biomarker evidence of IFD.

\section{Recommendations}

B1. In patients who are responding to initial empirical antibiotic therapy, discontinue double coverage for gram-negative infection or empirical glycopeptide (if initiated) after 24 to 72 hours if there is no specific microbiologic indication to continue combination therapy (strong recommendation, moderate-quality evidence).

B2. Do not modify the initial empirical antibacterial regimen based solely on persistent fever in children who are clinically stable (strong recommendation, low-quality evidence).

B3. In children with persistent fever who become clinically unstable, escalate the initial empirical antibacterial regimen to include coverage for resistant gram-negative, grampositive, and anaerobic bacteria (strong recommendation, very low-quality evidence).

Literature update and analysis. In the 2012 FN CPG, early discontinuation of combination therapy was based on the rationale for initial monotherapy without the addition of an aminoglycoside or empirical glycopeptide. As described previously, the recent systematic review confirmed the efficacy and safety of monotherapy without the addition of an aminoglycoside. ${ }^{34}$ The evidence remains indirect because the RCTs were in the setting of initial therapy and not ongoing therapy and consequently, this reduces the evidence quality to moderate.

There were no pediatric RCTs that evaluated the role of continuing empirical glycopeptides or the appropriate course of action in patients with persistent fever who remain clinically stable or who deteriorate. Thus, there were no changes to the 2012 recommendations.

\section{Question}

When can empirical antibiotics be discontinued in patients with low- and high-risk FN?

\section{Recommendations}

B4. In all patients, discontinue empirical antibiotics in patients who have negative blood cultures at 48 hours, who have been afebrile for at least 24 hours, and who have evidence of marrow recovery (strong recommendation, low-quality evidence).

B5. In patients with low-risk $\mathrm{FN}$, consider discontinuation of empirical antibiotics at 72 hours in patients who have negative blood cultures and who have been afebrile for at least 24 hours, irrespective of marrow recovery status, as long as careful follow-up is ensured (weak recommendation, moderate-quality evidence).

Literature update and analysis. The 2012 CPG recommendation to discontinue antibiotics in patients with negative blood cultures who have been afebrile for at least 24 hours and who have evidence of count recovery was based on a summary of both randomized and observational trials. ${ }^{55-74}$ In that analysis, the risk of recurrent fever was low in patients with definitive marrow recovery.

No new RCTs of antibiotic cessation were identified in our recent systematic review, ${ }^{34}$ and thus, the recommendations have not changed. Two RCTs included in the 2012 CPG compared early cessation with continuation of empirical antibiotics. ${ }^{58,75}$ Both studies were small and showed no differences in outcomes. However, it is notable that the two patients with bacteremia (viridans group streptococci and Enterobacter aerogenes) were both in the cessation arm. Importantly, a large proportion of patients in one study ${ }^{75}$ had evidence of marrow recovery at the time of random assignment, whereas this proportion was not stated in the second study. ${ }^{58}$ Thus, it remains a weak recommendation to discontinue antibiotics in lowrisk patients who have been afebrile for at least 24 hours but who have no evidence of count recovery on Day 3 , because the specific question of safety of antibiotic discontinuation without marrow recovery has not been directly addressed.

The optimal duration of empirical antibiotics for high-risk patients with sustained bone marrow suppression was not addressed in the systematic review ${ }^{34}$ and continues to be an important research gap.

\section{SECTION C: EMPIRICAL ANTIFUNGAL TREATMENT}

\section{Question}

What clinical parameters can classify pediatric patients with persistent FN as high risk or low risk of invasive fungal disease (IFD)?

\section{Recommendation}

C1. Patients at high risk of IFD are those with acute myeloid leukemia, high-risk acute lymphoblastic leukemia (ALL), or relapsed acute leukemia, and children undergoing allogeneic HSCT. Children with prolonged neutropenia and children receiving high-dose corticosteroids are also at high risk of IFD. All others should be categorized as IFD low risk (strong recommendation, low quality evidence).

Literature update and analysis. The updated CPG was modified based on a systematic review of risk factors for IFD specifically in pediatric oncology and HSCT recipients. ${ }^{75 a}$ This review included 22 studies $^{76-97}$ and confirmed most risk factors for IFD previously described in the 2012 CPG. However, additional factors now 


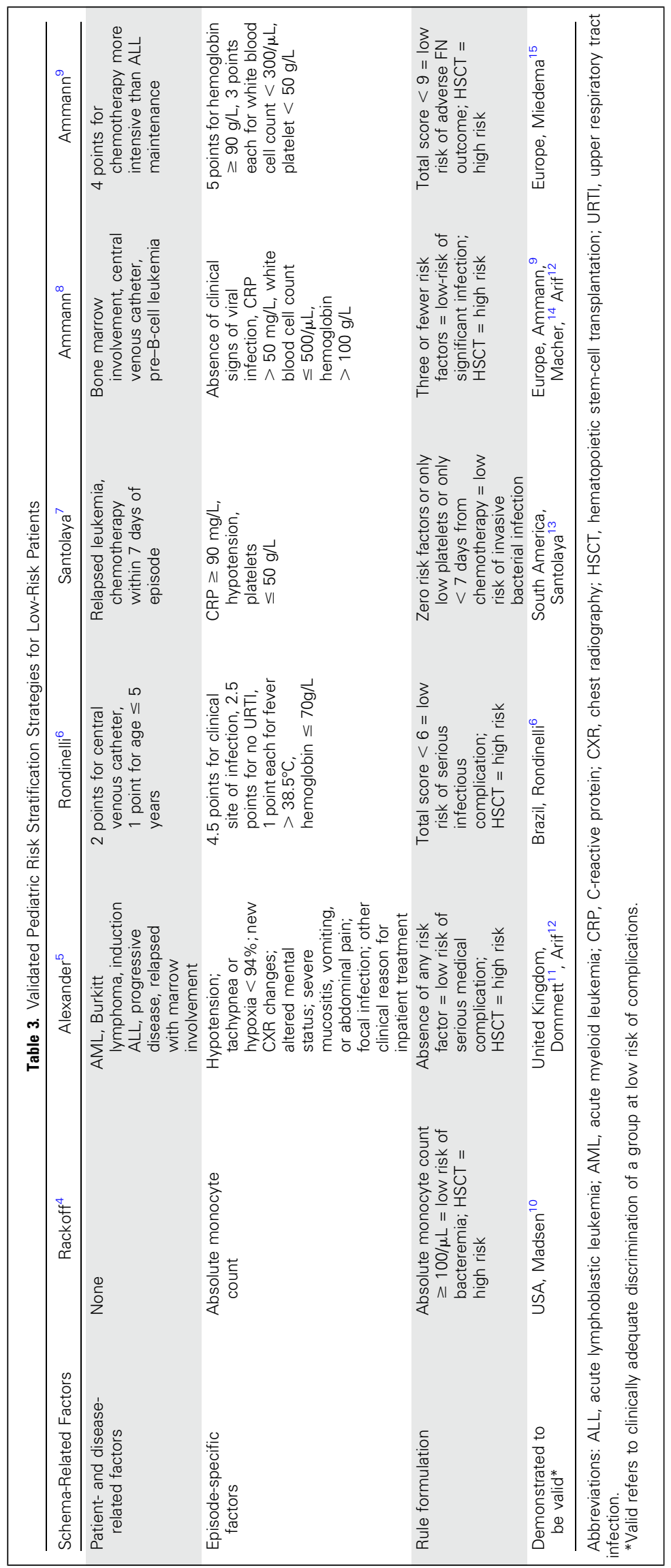


Table 4. Synthesized Outcomes for Comparisons of Different Antibiotic Strategies

\begin{tabular}{|c|c|c|c|c|c|}
\hline Failure with modification included & 9 & 672 & RR 1.13 & 0.92 to 1.38 & .23 \\
\hline Failure with modification excluded & 4 & 289 & RR 1.65 & 0.61 to 4.51 & .33 \\
\hline Infection-related mortality & 7 & 524 & RR 1.99 & 0.58 to 6.85 & .28 \\
\hline Days of antibiotics & 4 & 293 & MD 0.71 & -1.20 to 2.61 & .47 \\
\hline Adverse events & 5 & 437 & RR 0.93 & 0.54 to 1.60 & .79 \\
\hline \multicolumn{6}{|c|}{$\begin{array}{l}\text { Antipseudomonal penicillin monotherapy } v \\
\text { fourth-generation cephalosporin monotherapy } \dagger\end{array}$} \\
\hline Failure with modification included & 4 & 430 & RR 0.95 & 0.75 to 1.21 & .70 \\
\hline Infection-related mortality & 4 & 509 & RR 2.52 & 0.49 to 12.90 & .27 \\
\hline Days of fever & 3 & 296 & MD -0.03 & -0.96 to 0.89 & .94 \\
\hline Days of fever & 3 & 228 & MD -0.02 & -0.81 to 0.78 & .97 \\
\hline Days of antibiotics & 4 & 377 & MD 0.17 & -0.47 to 0.82 & .60 \\
\hline Days of hospitalization & 3 & 340 & MD 3.85 & 3.01 to 4.69 & $<.0001$ \\
\hline \multicolumn{6}{|l|}{ Intravenous $v$ oral empirical antibiotics $\dagger$} \\
\hline Failure with modification included & 4 & 526 & RR 0.95 & 0.72 to 1.24 & .70 \\
\hline Failure with modification excluded & 5 & 613 & RR 0.65 & 0.28 to 1.52 & .32 \\
\hline Infection-related mortality & 7 & 932 & No events & & \\
\hline Overall mortality & 6 & 816 & No events & & \\
\hline Readmission & 5 & 578 & RR 0.50 & 0.23 to 1.08 & .08 \\
\hline Intensive care unit & 4 & 462 & No events & & \\
\hline Days of fever & 6 & 758 & RR 0.14 & -0.27 to 0.56 & .50 \\
\hline Adverse events & 4 & 459 & RR 0.46 & 0.11 to 1.92 & .29 \\
\hline
\end{tabular}

specified include high-risk ALL and high-dose corticosteroids. The Panel recognized that high-risk ALL is a heterogeneous group and that the risk of IFD may be explained by prolonged neutropenia and corticosteroid administration. However, data to provide further specification around which patient with ALL is at particular risk of IFD and the treatment phases of elevated risk are not available.

\section{Question}

What clinical features, laboratory tests, and imaging studies are useful to identify a fungal cause for persistent or recurrent FN despite broad-spectrum antibiotics?

\section{Recommendations}

C2. In terms of biomarkers to guide empirical antifungal management for prolonged ( $\geq 96$ hours) FN in IFD highrisk patients:

C2a. Consider not using serum galactomannan (GM; weak recommendation, moderate-quality evidence).

C2b. Do not use $\beta$-D-glucan (BG; strong recommendation, lowquality evidence).

C2c. Do not use fungal polymerase chain reaction (PCR) testing in blood (strong recommendation, moderate-quality evidence).

C3. In terms of imaging for the evaluation of prolonged ( $\geq 96$ hours) FN in IFD high-risk patients:
C3a. Perform computed tomography (CT) of the lungs (strong recommendation, low-quality evidence).

C3b. Consider imaging of abdomen in patients without localizing signs or symptoms (weak recommendation, lowquality evidence).

C3c. Consider not routinely performing CT of sinuses in patients without localizing signs or symptoms (weak recommendation, low-quality evidence).

Literature update and analysis. In the 2012 CPG, we included recommendations related to surveillance and further investigation of identified foci of infection such as lung nodules. In this CPG update, we realized that these areas were outside of the scope of the FN CPG and thus, those recommendations have been removed.

The 2017 FN CPG altered the recommendation related to GM testing based on a recently conducted systematic review of fungal biomarkers in pediatric cancer and HSCT. ${ }^{98}$ Eight studies assessed GM as a diagnostic tool in children with symptoms potentially suggestive of IFD, such as prolonged FN. ${ }^{99-106}$ Among these studies, seven showed positive predictive values (PPV) $\leq 75 \%$, and four studies showed PPV $<50 \%$. Table 5 illustrates a clinical vignette of GM testing in a population with a $10 \%$ risk of invasive aspergillosis (IA) during FN and illustrates that using the pooled sensitivity and specificity of $89 \%$ and $85 \%$ from the systematic review, PPV would be $41 \%$ and negative predictive value (NPV) 
would be 97\%. Among 100 patients at high risk of IA evaluated, testing would miss one patient with true infection and would erroneously conclude IA in 14 patients without infection. Of the 23 children with a positive test, only nine would actually have IA; in other words, most patients with a positive test in this clinical setting will not have IA. The basis for the weak recommendation against use of GM during FN was the poor PPV, and the limited usefulness of high NPV because GM does not rule out non-Aspergillus molds.

The recommendation related to $B G$ testing remains unchanged. In the systematic review of biomarkers for IFD, ${ }^{98}$ only one study evaluated BG in an applicable setting, ${ }^{107}$ and it showed PPV of $49 \%$ (95\% CI, 32 to 66) and NPV of $96 \%$ (95\% CI, 89 to 99), precluding clinical usefulness.

The updated CPG includes a new strong recommendation against the use of fungal PCR in blood for evaluation of IFD during prolonged FN based on eight studies ${ }^{99,108-114}$ that applied PCR in a similar setting. ${ }^{109}$ Table 5 illustrates a clinical vignette of PCR testing in a population with a $10 \%$ risk of IFD during $\mathrm{FN}$ and illustrates that using the pooled sensitivity and specificity of $76 \%$ and 58\% from the systematic review, PPV would be $17 \%$ and NPV would be 95\%. Among 100 IFD high-risk patients evaluated, testing would miss two patients with true infection and would erroneously conclude IFD in 38 patients without infection. Of the 46 patients with a positive test, only eight would truly have IFD. The basis for the strong recommendation against use of PCR is the poor PPV and NPV, which were not sufficiently high to be clinically useful. The Panel also noted the current lack of standardization for PCR testing, which also makes clinical use challenging.

A limitation of the recommendations related to fungal biomarkers is how we approached them as diagnostic tests and evaluated their usefulness in detecting true disease. Randomized

\begin{tabular}{cc} 
Table 5. Clinical Implications of Fungal Biomarkers in the Diagnostic Setting \\
\hline GM & Fungal PCR \\
\hline Pooled sensitivity $=0.89$ & Pooled sensitivity $=0.76$ \\
Pooled specificity $=0.85$ & Pooled specificity $=0.58$ \\
Positive predictive & Positive predictive \\
value: 0.41 & value: 0.17 \\
Negative predictive & Negative predictive \\
value: 0.97 & value: 0.95 \\
23 children will have a & 46 children will have \\
positive test & a positive test \\
Nine will have IA & Eight will have IFD \\
(true positives) & (true positives) \\
14 will not have IA & 38 will not have IFD \\
(false positives) & (false positives) \\
77 will have a negative & 54 will have a negative \\
test & test \\
76 will not have IA (true & 52 will not have IFD \\
negatives) & (true negatives) \\
One will have IA (missed & Two will have IFD (missed \\
one of 10 with true & two of 10 children with \\
infection) & true infection)
\end{tabular}

NOTE. The table assumes that serum GM and fungal PCR are performed in 100 consecutive IFD high-risk patients with prolonged FN. The pretest probability (prevalence) of IFD in this high-risk population is estimated at 10\% (10 patients will truly have IFD). Pooled sensitivity and specificity were obtained from a systematic review of biomarkers. ${ }^{78}$ Predictive values were directly calculated assuming $10 \%$ prevalence of disease and using pooled sensitivity and specificity. Beta-D-glucan was not included because synthesis in FN setting was not possible, given the number of available studies.

Abbreviations: FN, fever and neutropenia; GM, galactomannan; IA, invasive aspergillosis; IFD, invasive fungal disease; PCR, polymerase chain reaction. trials comparing utilization with nonutilization of these biomarkers to detect IFD would be a better approach to evaluation, but such trials are unlikely to be feasible. In fact, our current standard to recommend empirical antifungal therapy for IFD highrisk patients with prolonged fever is based on the assumption that prolonged fever is a good predictor of IFD when this factor has never been evaluated as a diagnostic test. Comparative effectiveness studies of fungal biomarker use may be the best way to bridge this knowledge gap.

The data supporting recommendations related to imaging for the evaluation of IFD during prolonged FN are shown in the Data Supplement. A strong recommendation to perform lung CTs remained unchanged in the updated CPG. Of the nine studies evaluating lung $\mathrm{CT}^{115-123}$ for the evaluation of IFD, lungs were usually the most frequent site of infection, and characteristic radiographic signs were often observed. A new weak recommendation for abdominal imaging even in the absence of localizing signs or symptoms was made with this CPG update, based on the systematic review (Data Supplement). Among the four studies included, ${ }^{118,122-124}$ findings on imaging consistent with IFD were observed in many patients without localizing signs or symptoms. The Panel noted that the ideal imaging modality is not known, but ultrasound is readily available, is not associated with radiation exposure, and usually does not require sedation and thus, is likely preferable over CT or magnetic resonance imaging for abdominal assessment.

In the updated CPG, a revised weak recommendation against routine sinus imaging was made in the absence of localizing signs or symptoms based on the systematic review (Data Supplement). Among the five studies that described sinus findings, ${ }^{118,122,123,125,126}$ sinus imaging was frequently abnormal in prolonged $\mathrm{FN}$, and abnormalities did not distinguish between those with and without sinus IFD. It is a weak recommendation because studies directly addressing the usefulness of routine sinus CTs were limited.

\section{Question}

When should empirical antifungal therapy be initiated, what antifungal agents are appropriate, and when is it appropriate to discontinue empirical therapy?

\section{Recommendations}

C4. In IFD high-risk patients with prolonged ( $\geq 96$ hours) FN unresponsive to broad-spectrum antibacterial agents, initiate caspofungin or liposomal amphotericin B (L-AmB) for empirical antifungal therapy (strong recommendation, high-quality evidence).

C5. In IFD low-risk patients with prolonged ( $\geq 96$ hours) FN, consider withholding empirical antifungal therapy (weak recommendation, low-quality evidence).

Literature update and analysis. Recommendations regarding the choice of empirical antifungal agents in IFD high-risk patients remain unchanged from the $2012 \mathrm{FN}$ CPG, but they are changed in IFD low-risk patients. Recommendations in IFD high-risk patients were originally based on three RCTs ${ }^{127-129}$ demonstrating that caspofungin was as effective as L-AmB, ${ }^{127,128}$ and that L-AmB was less nephrotoxic than amphotericin B deoxycholate. ${ }^{129}$ Either caspofungin or L-AmB was strongly recommended as empirical 
antifungal therapy. One recent study prospectively compared administration of empirical antifungal therapy versus withholding empirical antifungal therapy in neutropenic children with persistent fever who were IFD low-risk. No benefit relative to fever resolution or IFD was detected from empirical antifungal therapy. ${ }^{127}$

No RCTs addressed empirical antifungal therapy cessation or a pre-emptive antifungal therapy approach and thus, original recommendations were unchanged. Both of these areas remain important knowledge gaps in pediatric FN.

\section{DISCUSSION}

We updated the 2012 FN CPG for children with cancer and HSCT recipients. Although most recommendations remained unchanged, some key differences emerged. Changes included the listing of a fourth-generation cephalosporin for empirical therapy, refinement of IFD risk stratification, changes in recommended biomarkers and radiologic investigations for the evaluation of IFD, and a weak recommendation to withhold empirical antifungal therapy in IFD low-risk patients.

Implementation is an important issue, and national and international guidance will be important to effect change. Adaptation will be required at the institutional level to delineate specific rather than generic antibiotic choices and to decide whether to implement or not implement weak recommendations. Decision making for weak recommendations could also be made at the specific provider or patient level. Cost-effectiveness studies may be relevant when deciding whether to implement weak recommendations.

Changes to the updated FN CPG recommendations will likely influence the care of children with cancer and pediatric patients undergoing HSCT. Future work should focus on closing research gaps and identifying ways to facilitate implementation.

\section{AUTHORS' DISCLOSURES OF POTENTIAL CONFLICTS} OF INTEREST

Disclosures provided by the authors are available with this article at jco.org.

\section{AUTHOR CONTRIBUTIONS}

Conception and design: Thomas Lehrnbecher, Paula Robinson, Robert Phillips, Brian Fisher, Lillian Sung

Financial support: Lillian Sung

Administrative support: Paula Robinson, Lillian Sung

Collection and assembly of data: Thomas Lehrnbecher, Paula Robinson, Robert Phillips, Brian Fisher, Lillian Sung

Data analysis and interpretation: All authors

Manuscript writing: All authors

Final approval of manuscript: All authors

Accountable for all aspects of the work: All authors

\section{REFERENCES}

1. Lehrnbecher $T$, Phillips $R$, Alexander $S$, et al: Guideline for the management of fever and neutropenia in children with cancer and/or undergoing hematopoietic stem-cell transplantation. J Clin Oncol 30:4427-4438, 2012

2. Oxman $A D$, Fretheim $A$, Schünemann $H J$ : Improving the use of research evidence in guideline development: introduction. Health Res Policy Syst 4 : 12, 2006

3. Brouwers MC, Kho ME, Browman GP, et al: Development of the AGREE II, part 1: Performance, usefulness and areas for improvement. CMAJ 182: 1045-1052, 2010

4. Rackoff WR, Gonin R, Robinson C, et al: Predicting the risk of bacteremia in childen with fever and neutropenia. J Clin Oncol 14:919-924, 1996

5. Alexander SW, Wade $\mathrm{KC}$, Hibberd $\mathrm{PL}$, et al: Evaluation of risk prediction criteria for episodes of febrile neutropenia in children with cancer. J Pediatr Hematol Oncol 24:38-42, 2002

6. Rondinelli PI, Ribeiro Kde C, de Camargo B: A proposed score for predicting severe infection complications in children with chemotherapy-induced febrile neutropenia. J Pediatr Hematol Oncol 28: 665-670, 2006

7. Santolaya ME, Alvarez AM, Becker $A$, et al: Prospective, multicenter evaluation of risk factors associated with invasive bacterial infection in children with cancer, neutropenia, and fever. J Clin Oncol 19:3415-3421, 2001

8. Ammann RA, Hirt A, Lüthy AR, et al: Identification of children presenting with fever in chemotherapyinduced neutropenia at low risk for severe bacterial infection. Med Pediatr Oncol 41:436-443, 2003
9. Ammann RA, Bodmer N, Hirt A, et al: Predicting adverse events in children with fever and chemotherapy-induced neutropenia: The prospective multicenter SPOG 2003 FN study. J Clin Oncol 28: 2008-2014, 2010

10. Madsen K, Rosenman M, Hui S, et al: Value of electronic data for model validation and refinement: Bacteremia risk in children with fever and neutropenia. J Pediatr Hematol Oncol 24:256-262, 2002

11. Dommett $R$, Geary J, Freeman $S$, et al: Successful introduction and audit of a step-down oral antibiotic strategy for low risk paediatric febrile neutropaenia in a UK, multicentre, shared care setting. Eur J Cancer 45:2843-2849, 2009

12. Arif T, Sutcliffe R, Hewitt M, et al: G239 validation of two risk stratification guidelines in a one year cohort of febrile admissions in paediatric oncology patients in a UK centre. Arch Dis Child 99:A103, 2014

13. Santolaya $M E$, Alvarez $A M$, Avilés $C L$, et al: Prospective evaluation of a model of prediction of invasive bacterial infection risk among children with cancer, fever, and neutropenia. Clin Infect Dis 35: 678-683, 2002

14. Macher E, Dubos F, Garnier N, et al: Predicting the risk of severe bacterial infection in children with chemotherapy-induced febrile neutropenia. Pediatr Blood Cancer 55:662-667, 2010

15. Miedema KG, de Bont ES, Oude Nijhuis CS, et al: Validation of a new risk assessment model for predicting adverse events in children with fever and chemotherapy-induced neutropenia. J Clin Oncol 29: e182-e184; author reply e185, 2011

16. Phillips RS, Lehrnbecher T, Alexander $S$, et al: Updated systematic review and meta-analysis of the performance of risk prediction rules in children and young people with febrile neutropenia. PLoS One 7: e38300, 2012
17. Miedema KG, Tissing WJ, Abbink FC, et al: Risk-adapted approach for fever and neutropenia in paediatric cancer patients-a national multicentre study. Eur J Cancer 53:16-24, 2016

18. Santolaya ME, Alvarez $A M$, Avilés $C L$, et al: Prospective validation of a risk prediction model for severe sepsis in children with cancer and high-risk febrile neutropenia. Pediatr Infect Dis J 32:1318-1323, 2013

19. Handrup MM, Møller JK, Rutkjaer $C$, et al: Importance of blood cultures from peripheral veins in pediatric patients with cancer and a central venous line. Pediatr Blood Cancer 62:99-102, 2015

20. Leblanc D, Bartel N, Velasco-Gonzales C, et al: The utility of peripheral blood cultures in febrile pediatric oncology patients. Pediatr Blood Cancer 61: S56, 2014

21. Rodríguez L, Ethier M-C, Phillips $B$, et al: Utility of peripheral blood cultures in patients with cancer and suspected blood stream infections: A systematic review. Support Care Cancer 20:3261-3267, 2012

22. DesJardin JA, Falagas ME, Ruthazer $R$, et al: Clinical utility of blood cultures drawn from indwelling central venous catheters in hospitalized patients with cancer. Ann Intern Med 131:641-647, 1999

23. Chen WT, Liu TM, Wu SH, et al: Improving diagnosis of central venous catheter-related bloodstream infection by using differential time to positivity as a hospital-wide approach at a cancer hospital. J Infect 59:317-323, 2009

24. Adamkiewicz TV, Lorenzana A, Doyle J, et al: Peripheral vs. central blood cultures in patients admitted to a pediatric oncology ward. Pediatr Infect Dis J 18:556-558, 1999

25. Raad I, Hanna HA, Alakech B, et al: Differential time to positivity: A useful method for diagnosing 
catheter-related bloodstream infections. Ann Intern Med 140:18-25, 2004

26. Handrup MM, Moller JK, Schroder $\mathrm{H}$ : Catheter-related bloodstream infections in children with cancer admitted with fever. 42nd Congress of the International Society of Pediatric Oncology (SIOP), Boston, MA, October 21-24, 2010

27. Barriga FJ, Varas $M$, Potin $M$, et al: Efficacy of a vancomycin solution to prevent bacteremia associated with an indwelling central venous catheter in neutropenic and non-neutropenic cancer patients. Med Pediatr Oncol 28:196-200, 1997

28. Sandoval $C$, Sinaki $B$, Weiss $R$, et al: Urinary tract infections in pediatric oncology patients with fever and neutropenia. Pediatr Hematol Oncol 29: 68-72, 2012

29. Klaassen IL, de Haas V, van Wijk JA, et al: Pyuria is absent during urinary tract infections in neutropenic patients. Pediatr Blood Cancer 56: 868-870, 2011

30. Mori R, Yonemoto N, Fitzgerald A, et al: Diagnostic performance of urine dipstick testing in children with suspected UTI: A systematic review of relationship with age and comparison with microscopy. Acta Paediatr 99:581-584, 2010

31. Roberts SD, Wells GM, Gandhi NM, et al: Diagnostic value of routine chest radiography in febrile, neutropenic children for early detection of pneumonia and mould infections. Support Care Cancer 20:2589-2594, 2012

32. Cox JA, DeMasi J, McCollom S, et al: The diagnostic utility of routine chest radiography in the evaluation of the initial fever in patients undergoing hematopoietic stem cell. Pediatr Blood Cancer 57: 666-668, 2011

33. Renoult E, Buteau C, Turgeon N, et al: Is routine chest radiography necessary for the initial evaluation of fever in neutropenic children with cancer? Pediatr Blood Cancer 43:224-228, 2004

34. Robinson PD, Lehrnbecher T, Phillips R, et al: Strategies for empiric management of pediatric fever and neutropenia in patients with cancer and hematopoietic stem-cell transplantation recipients: A systematic review of randomized trials. J Clin Oncol 34:2054-2060, 2016

35. Pereira CA, Petrilli AS, Carlesse FA, et al: Cefepime monotherapy is as effective as ceftriaxone plus amikacin in pediatric patients with cancer and high-risk febrile neutropenia in a randomized comparison. J Microbiol Immunol Infect 42:141-147, 2009

36. Petrilli AS, Cypriano M, Dantas LS, et al: Evaluation of ticarcillin/clavulanic acid versus ceftriaxone plus amikacin for fever and neutropenia in pediatric patients with leukemia and lymphoma. Braz $\mathrm{J}$ Infect Dis 7:111-120, 2003

37. El Haddad AMA: Comparison of cefoperazonesulbactam versus piperacillin plus amikacin as empiric therapy in pediatric febrile neutropenic cancer patients. Curr Ther Res Clin Exp 56:1094-1099, 1995

38. Ichikawa M, Suzuki D, Ohshima J, et al: Piperacillin/tazobactam versus cefozopran for the empirical treatment of pediatric cancer patients with febrile neutropenia. Pediatr Blood Cancer 57:1159-1162, 2011

39. Uygun V, Karasu GT, Ogunc D, et al: Piperacillin/tazobactam versus cefepime for the empirical treatment of pediatric cancer patients with neutropenia and fever: A randomized and open-label study. Pediatr Blood Cancer 53:610-614, 2009

40. Corapcioglu F, Sarper N, Zengin E: Monotherapy with piperacillin/tazobactam versus cefepime as empirical therapy for febrile neutropenia in pediatric cancer patients: A randomized comparison. Pediatr Hematol Oncol 23:177-186, 2006

41. Sano H, Kobayashi R, Suzuki D, et al: Comparison between piperacillin/tazobactam and cefepime monotherapies as an empirical therapy for febrile neutropenia in children with hematological and malignant disorders: A prospective, randomized study. Pediatr Blood Cancer 62:356-358, 2015

42. Aamir M, Abrol $P$, Sharma $D$, et al: A clinical evaluation of efficacy and safety of cefepime monotherapy versus piperacillin-tazobactam in patients of paediatric age group with febrile neutropenia in a tertiary care centre of north India. Trop Doct 46 : 142-148, 2016

43. Orme LM, Babl FE, Barnes C, et al: Outpatient versus inpatient IV antibiotic management for pediatric oncology patients with low risk febrile neutropenia: A randomised trial. Pediatr Blood Cancer 61 1427-1433, 2014

44. Brack E, Bodmer N, Simon A, et al: First-day step-down to oral outpatient treatment versus continued standard treatment in children with cancer and low-risk fever in neutropenia. A randomized controlled trial within the multicenter SPOG 2003 FN study. Pediatr Blood Cancer 59:423-430, 2012

45. Ahmed N, El-Mahallawy HA, Ahmed IA, et al: Early hospital discharge versus continued hospitalization in febrile pediatric cancer patients with prolonged neutropenia: A randomized, prospective study. Pediatr Blood Cancer 49:786-792, 2007

46. Santolaya ME, Alvarez AM, Avilés $C L$, et al: Early hospital discharge followed by outpatient management versus continued hospitalization of children with cancer, fever, and neutropenia at low risk for invasive bacterial infection. J Clin Oncol 22 3784-3789, 2004

47. Cagol AR, Castro Junior CG, Martins MC, et al: Oral vs. intravenous empirical antimicrobial therapy in febrile neutropenic patients receiving childhood cancer chemotherapy. J Pediatr (Rio J) 85:531-535, 2009

48. Gupta A, Swaroop C, Agarwala S, et al: Randomized controlled trial comparing oral amoxicillinclavulanate and ofloxacin with intravenous ceftriaxone and amikacin as outpatient therapy in pediatric low-risk febrile neutropenia. J Pediatr Hematol Onco 31:635-641, 2009

49. Paganini H, Gómez S, Ruvinsky S, et al: Outpatient, sequential, parenteral-oral antibiotic therapy for lower risk febrile neutropenia in children with malignant disease: A single-center, randomized, controlled trial in Argentina. Cancer 97:1775-1780, 2003

50. Paganini $H$, Rodriguez-Brieshcke $T$, Zubizarreta $P$, et al: Oral ciprofloxacin in the management of children with cancer with lower risk febrile neutropenia. Cancer 91:1563-1567, 2001

51. Shenep JL, Flynn PM, Baker DK, et al: Oral cefixime is similar to continued intravenous antibiotics in the empirical treatment of febrile neutropenic children with cancer. Clin Infect Dis 32:36-43, 2001

52. Paganini HR, Sarkis CM, De Martino MG, et al: Oral administration of cefixime to lower risk febrile neutropenic children with cancer. Cancer 88:2848-2852 2000

53. Petrilli AS, Dantas LS, Campos MC, et al: Ora ciprofloxacin vs. intravenous ceftriaxone administered in an outpatient setting for fever and neutropenia in lowrisk pediatric oncology patients: Randomized prospective trial. Med Pediatr Oncol 34:87-91, 2000

54. Mullen CA, Petropoulos D, Roberts WM, et al: Outpatient treatment of fever and neutropenia for low risk pediatric cancer patients. Cancer 86:126-134, 1999

55. Oude Nijhuis C, Kamps WA, Daenen SM, et al: Feasibility of withholding antibiotics in selected febrile neutropenic cancer patients. J Clin Oncol 23: 7437-7444, 2005

56. Aquino VM, Buchanan GR, Tkaczewski l, et al: Safety of early hospital discharge of selected febrile children and adolescents with cancer with prolonged neutropenia. Med Pediatr Oncol 28:191-195, 1997

57. Pizzo PA, Robichaud KJ, Gill FA, et al: Duration of empiric antibiotic therapy in granulocytopenic patients with cancer. Am J Med 67:194-200, 1979

58. Santolaya ME, Villarroel M, Avendaño LF, et al: Discontinuation of antimicrobial therapy for febrile, neutropenic children with cancer: A prospective study. Clin Infect Dis 25:92-97, 1997

59. Wacker $P$, Halperin DS, Wyss M, et al: Early hospital discharge of children with fever and neutropenia: A prospective study. J Pediatr Hematol Oncol 19:208-211, 1997

60. Cohen KJ, Leamer K, Odom L, et al: Cessation of antibiotics regardless of ANC is safe in children with febrile neutropenia. A preliminary prospective trial. J Pediatr Hematol Oncol 17:325-330, 1995

61. Bash RO, Katz JA, Cash JV, et al: Safety and cost effectiveness of early hospital discharge of lower risk children with cancer admitted for fever and neutropenia. Cancer 74:189-196, 1994

62. Hodgson-Viden $\mathrm{H}$, Grundy PE, Robinson JL: Early discontinuation of intravenous antimicrobial therapy in pediatric oncology patients with febrile neutropenia. BMC Pediatr 5:10, 2005

63. Lehrnbecher T, Stanescu A, Kühl J: Short courses of intravenous empirical antibiotic treatment in selected febrile neutropenic children with cancer. Infection 30:17-21, 2002

64. Griffin TC, Buchanan GR: Hematologic predictors of bone marrow recovery in neutropenic patients hospitalized for fever: Implications for discontinuation of antibiotics and early discharge from the hospital. J Pediatr 121:28-33, 1992

65. Kaplan AH, Weber DJ, Davis L, et al: Short courses of antibiotics in selected febrile neutropenic patients. Am J Med Sci 302:353-354, 1991

66. Mullen CA, Buchanan GR: Early hospital discharge of children with cancer treated for fever and neutropenia: Identification and management of the low-risk patient. J Clin Oncol 8:1998-2004, 1990

67. Aquino VM, Tkaczewski I, Buchanan GR: Early discharge of low-risk febrile neutropenic children and adolescents with cancer. Clin Infect Dis 25:74-78, 1997

68. Slobbe L, Waal Lv, Jongman LR, et al: Threeday treatment with imipenem for unexplained fever during prolonged neutropaenia in haematology patients receiving fluoroquinolone and fluconazole prophylaxis: a prospective observational safety study. Eur J Cancer 45:2810-2817, 2009

69. Cornelissen JJ, Rozenberg-Arska M, Dekker AW: Discontinuation of intravenous antibiotic therapy during persistent neutropenia in patients receiving prophylaxis with oral ciprofloxacin. Clin Infect Dis 21 1300-1302, 1995

70. de Marie S, van den Broek PJ, Willemze R, et al: Strategy for antibiotic therapy in febrile neutropenic patients on selective antibiotic decontamination. Eur $\mathrm{J}$ Clin Microbiol Infect Dis 12:897-906, 1993

71. Joshi JH, Schimpff SC, Tenney JH, et al: Can antibacterial therapy be discontinued in persistently febrile granulocytopenic cancer patients? Am J Med 76:450-457, 1984

72. Björnsson S, Preisler $H$, Henderson ES: A study of antibiotic therapy in fever of unknown origin in neutropenic cancer patients. Med Pediatr Oncol 3 : 379-385, 1977

73. Mahendra $P$, Jacobson SK, Ager S, et al: Shortcourse intravenous antibiotics with oral quinolone 
prophylaxis in the treatment of neutropenic fever in autologous bone marrow or peripheral blood progenitor cell transplant recipients. Acta Haematol 96: 64-67, 1996

74. Tomiak AT, Yau JC, Huan SD, et al: Duration of intravenous antibiotics for patients with neutropenic fever. Ann Oncol 5:441-445, 1994

75. Klaassen RJ, Allen U, Doyle JJ: Randomized placebo-controlled trial of oral antibiotics in pediatric oncology patients at low-risk with fever and neutropenia. J Pediatr Hematol Oncol 22:405-411, 2000

75a. Fisher $B$, Robinson $P$, Lehrnbecher $T$, et al: Risk factors for invasive fungal disease in pediatric cancer and hematopoietic stem cell transplantation: A systematic review. J Pediatric Infect Dis Soc. In press

76. Johnston DL, Lewis $V$, Yanofsky $R$, et al: Invasive fungal infections in paediatric acute myeloid leukaemia. Mycoses 56:482-487, 2013

77. Castagnola $E$, Bagnasco $F$, Bandettini $R$, et al: Role of acute graft-versus-host disease in the risk of bacteremia and invasive fungal disease after allogeneic hemopoietic stem cell transplantation in children. Results from a single-center observational study. Biol Blood Marrow Transplant 20:1068-1073, 2014

78. Hol JA, Wolfs TF, Bierings MB, et al: Predictors of invasive fungal infection in pediatric allogeneic hematopoietic SCT recipients. Bone Marrow Transplant 49:95-101, 2014

79. Srinivasan A, Wang C, Srivastava DK, et al: Timeline, epidemiology, and risk factors for bacterial, fungal, and viral infections in children and adolescents after allogeneic hematopoietic stem cell transplantation. Biol Blood Marrow Transplant 19:94-101, 2013

80. Satwani $P$, Baldinger $L$, Freedman $J$, et al: Incidence of viral and fungal infections following busulfan-based reduced-intensity versus myeloablative conditioning in pediatric allogeneic stem cell transplantation recipients. Biol Blood Marrow Transplant 15:1587-1595, 2009

81. Kobayashi R, Kaneda M, Sato $T$, et al: Evaluation of risk factors for invasive fungal infection after allogeneic stem cell transplantation in pediatric patients. J Pediatr Hematol Oncol 29:786-791, 2007

82. Dvorak CC, Steinbach WJ, Brown JM, et al: Risks and outcomes of invasive fungal infections in pediatric patients undergoing allogeneic hematopoietic cell transplantation. Bone Marrow Transplant 36 : 621-629, 2005

83. Benjamin DK, Jr., Miller WC, Bayliff $S$, et al: Infections diagnosed in the first year after pediatric stem cell transplantation. Pediatr Infect Dis J 21: 227-234, 2002

84. Hovi L, Saarinen-Pihkala UM, Vettenranta K, et al: Invasive fungal infections in pediatric bone marrow transplant recipients: Single center experience of 10 years. Bone Marrow Transplant 26:999-1004, 2000

85. Jain S, Kapoor G: Invasive aspergillosis in children with acute leukemia at a resource-limited oncology center. J Pediatr Hematol Oncol 37:e1-e5, 2015

86. Castagnola E, Rossi MR, Cesaro $S$, et al: Incidence of bacteremias and invasive mycoses in children with acute non-lymphoblastic leukemia: Results from a multi-center Italian study. Pediatr Blood Cancer 55:1103-1107, 2010

87. Sung L, Gamis A, Alonzo TA, et al: Infections and association with different intensity of chemotherapy in children with acute myeloid leukemia. Cancer 115:1100-1108, 2009

88. Castagnola E, Caviglia I, Pistorio A, et al: Bloodstream infections and invasive mycoses in children undergoing acute leukaemia treatment: a 13year experience at a single Italian institution. Eur J Cancer 41:1439-1445, 2005
89. Rosen GP, Nielsen K, Glenn S, et al: Invasive fungal infections in pediatric oncology patients: 11year experience at a single institution. J Pediatr Hematol Oncol 27:135-140, 2005

90. McCullers JA, Vargas SL, Flynn PM, et al: Candidal meningitis in children with cancer. Clin Infect Dis 31:451-457, 2000

91. Villarroel $M$, Avilés $C L$, Silva $P$, et al: Risk factors associated with invasive fungal disease in children with cancer and febrile neutropenia: A prospective multicenter evaluation. Pediatr Infect Dis J 29:816-821, 2010

92. Lucero $Y$, Brücher $R$, Alvarez AM, et al: Invasive fungal infections in children with cancer, neutropenia and fever, in Chile [in Spansh]. Rev Med Chil 130:1139-1146, 2002

93. Wiley JM, Smith N, Leventhal BG, et al: Invasive fungal disease in pediatric acute leukemia patients with fever and neutropenia during induction chemotherapy: A multivariate analysis of risk factors. $\mathrm{J}$ Clin Oncol 8:280-286, 1990

94. Styczynski J, Czyzewski K, Wysocki M, et al: Increased risk of infections and infection-related mortality in children undergoing haematopoietic stem cell transplantation compared to conventional anticancer therapy: a multicentre nationwide study. Clin Microbiol Infect 22:179.e1-179 e10, 2016

95. Babor F, Schuster F, Mackenzie C, et al: Invasive aspergillosis in pediatric oncology patients: $A$ rare event with poor prognosis-case analysis to plan better targeted prophylactic or therapeutic measurement. Klin Padiatr 224:160-165, 2012

96. Hale KA, Shaw PJ, Dalla-Pozza L, et al: Epidemiology of paediatric invasive fungal infections and a casecontrol study of risk factors in acute leukaemia or post stem cell transplant. Br J Haematol 149:263-272, 2010

97. Lai HP, Chen $Y C$, Chang $L Y$, et al: Invasive fungal infection in children with persistent febrile neutropenia. J Formos Med Assoc 104:174-179, 2005

98. Lehrnbecher T, Robinson PD, Fisher BT, et al: Galactomannan, $\beta$-D-glucan, and polymerase chain reaction-based assays for the diagnosis of invasive fungal disease in pediatric cancer and hematopoietic stem cell transplantation: A systematic review and meta-analysis. Clin Infect Dis 63:1340-1348, 2016

99. El-Mahallawy $\mathrm{HA}$, Shaker $\mathrm{HH}$, Ali Helmy $\mathrm{H}$, et al: Evaluation of pan-fungal PCR assay and Aspergillus antigen detection in the diagnosis of invasive fungal infections in high risk paediatric cancer patients. Med Mycol 44:733-739, 2006

100. Choi SH, Kang ES, Eo H, et al: Aspergillus galactomannan antigen assay and invasive aspergillosis in pediatric cancer patients and hematopoietic stem cell transplant recipients. Pediatr Blood Cancer 60:316-322, 2013

101. Dinand V, Anjan M, Oberoi JK, et al: Threshold of galactomannan antigenemia positivity for early diagnosis of invasive aspergillosis in neutropenic children. J Microbiol Immunol Infect 49:66-73, 2016

102. de Mol M, de Jongste JC, van Westreenen M, et al: Diagnosis of invasive pulmonary aspergillosis in children with bronchoalveolar lavage galactomannan. Pediatr Pulmonol 48:789-796, 2013

103. Armenian $\mathrm{SH}$, Nash KA, Kapoor N, et al: Prospective monitoring for invasive aspergillosis using galactomannan and polymerase chain reaction in high risk pediatric patients. J Pediatr Hematol Oncol 31:920-926, 2009

104. Castagnola E, Furfaro E, Caviglia I, et al: Performance of the galactomannan antigen detection test in the diagnosis of invasive aspergillosis in children with cancer or undergoing haemopoietic stem cell transplantation. Clin Microbiol Infect 16:1197-1203, 2010
105. Jha AK, Bansal D, Chakrabarti A, et al: Serum galactomannan assay for the diagnosis of invasive aspergillosis in children with haematological malignancies. Mycoses 56:442-448, 2013

106. Reinwald $M$, Konietzka CA, Kolve $H$, et al: Assessment of Aspergillus-specific PCR as a screening method for invasive aspergillosis in paediatric cancer patients and allogeneic haematopoietic stem cell recipients with suspected infections. Mycoses 57:537-543, 2014

107. Zhao L, Tang JY, Wang $Y$, et al: Value of plasma beta-Glucan in early diagnosis of invasive fungal infection in children [in Chinese]. Zhongguo Dang Dai Er Ke Za Zhi 11:905-908, 2009

108. Lin MT, Lu HC, Chen WL: Improving efficacy of antifungal therapy by polymerase chain reaction-based strategy among febrile patients with neutropenia and cancer. Clin Infect Dis 33:1621-1627, 2001

109. Lehrnbecher $T$, Robinson PD, Fisher BT, et al: Galactomannan, beta-D-glucan, and polymerase chain reaction-based assays for the diagnosis of invasive fungal disease in pediatric cancer and hematopoietic stem cell transplantation: A systematic review and meta-analysis. Clin Infect Dis 63:1340-1348, 2016

110. Cesaro S, Stenghele C, Calore $E$, et al: Assessment of the lightcycler PCR assay for diagnosis of invasive aspergillosis in paediatric patients with oncohaematological diseases. Mycoses 51:497-504, 2008

111. Hummel $M$, Spiess $B$, Roder J, et al: Detection of Aspergillus DNA by a nested PCR assay is able to improve the diagnosis of invasive aspergillosis in paediatric patients. J Med Microbiol 58:1291-1297, 2009

112. Landlinger $C$, Preuner $S$, Bašková $L$, et al: Diagnosis of invasive fungal infections by a real-time panfungal PCR assay in immunocompromised pediatric patients. Leukemia 24:2032-2038, 2010

113. Mandhaniya $S$, lqbal $S$, Sharawat $S K$, et al: Diagnosis of invasive fungal infections using realtime PCR assay in paediatric acute leukaemia induction. Mycoses 55:372-379, 2012

114. Reinwald $M$, Hummel $M$, Kovalevskaya $E$, et al: Therapy with antifungals decreases the diagnostic performance of PCR for diagnosing invasive aspergillosis in bronchoalveolar lavage samples of patients with haematological malignancies. J Antimicrob Chemother 67:2260-2267, 2012

115. Han SB, Kim SK, Bae EY, et al: Clinical features and prognosis of invasive pulmonary aspergillosis in Korean children with hematologic/oncologic siseases. J Korean Med Sci 30:1121-1128, 2015

116. Batra S, Li B, Underhill $N$, et al: Clinical utility of bronchoalveolar lavage and respiratory tract biopsies in diagnosis and management of suspected invasive respiratory fungal infections in children. Pediatr Blood Cancer 62:1579-1586, 2015

117. Gasparetto TD, Escuissato DL, Marchiori E: Pulmonary infections following bone marrow transplantation: High-resolution CT findings in 35 paediatric patients. Eur J Radiol 66:117-121, 2008

118. Archibald S, Park J, Geyer JR, et al: Computed tomography in the evaluation of febrile neutropenic pediatric oncology patients. Pediatr Infect Dis J 20: 5-10, 2001

119. Winer-Muram $H T$, Arheart $K L$, Jennings $S G$, et al: Pulmonary complications in children with hematologic malignancies: Accuracy of diagnosis with chest radiography and CT. Radiology 204:643-649, 1997

120. Taccone A, Occhi M, Garaventa A, et al: CT of invasive pulmonary aspergillosis in children with cancer. Pediatr Radiol 23:177-180, 1993

121. Irga $N$, Kosiak W, Szalewska $M$, et al: Invasive fungal infections in children treated for oncohematologic 
disorders - Selected diagnostic and therapeutic issues [in Polish]. Onkologia Polska 13:185-190, 2010

122. Ahmad Sarji S, Wan Abdullah W, Wastie M: Imaging features of fungal infection in immunosuppressed patients in a local ward outbreak. Biomed Imaging Interv J 2:e21, 2006

123. Cohn SM, Pokala HR, Siegel JD, et al: Application of a standardized screening protocol for diagnosis of invasive mold infections in children with hematologic malignancies. Support Care Cancer 24 5025-5033, 2016
124. Bartley DL, Hughes WT, Parvey LS, et al: Computed tomography of hepatic and splenic fungal abscesses in leukemic children. Pediatr Infect Dis 1 : 317-321, 1982

125. Park $A H$, Muntz HR, Smith ME, et al: Pediatric invasive fungal rhinosinusitis in immunocompromised children with cancer. Otolaryngol Head Neck Surg 133: 411-416, 2005

126. Kavanagh KT, Hughes WT, Parham DM, et al: Fungal sinusitis in immunocompromised children with neoplasms. Ann Otol Rhinol Laryngol 100:331-336, 1991
127. Caselli D, Cesaro S, Ziino O, et al: A prospective, randomized study of empirical antifungal therapy for the treatment of chemotherapy-induced febrile neutropenia in children. Br J Haematol 158:249-255, 2012

128. Maertens JA, Madero L, Reilly AF, et al: A randomized, double-blind, multicenter study of caspofungin versus liposomal amphotericin B for empiric antifungal therapy in pediatric patients with persistent fever and neutropenia. Pediatr Infect Dis J 29:415-420, 2010

129. Sandler ES, Mustafa MM, Tkaczewski I, et al: Use of amphotericin B colloidal dispersion in children. J Pediatr Hematol Oncol 22:242-246, 2000

\section{Affiliations}

Thomas Lehrnbecher, Hospital for Children and Adolescents, Johann Wolfgang Goethe University, Frankfurt; Andreas H. Groll, University Children's Hospital, Muenster, Germany; Paula Robinson, Pediatric Oncology Group of Ontario; Sarah Alexander, L. Lee Dupuis, and Lillian Sung, The Hospital for Sick Children, Toronto, Ontario, Canada; Brian Fisher and Theo Zaoutis, Children's Hospital of Philadelphia, Philadelphia, PA; Roland A. Ammann, Bern University Hospital, University of Bern, Switzerland; Melissa Beauchemin, Columbia University/Herbert Irving Cancer Center, New York, NY; Fabianne Carlesse, Pediatric Oncology Institute, GRAACC/Federal University of Sao Paulo, Sao Paulo, Brazil; Gabrielle M. Haeusler, Peter MacCallum Cancer Centre, Melbourne; Monash Children's Hospital, Clayton, Victoria, Australia; Maria Santolaya, Hospital Luis Calvo Mackenna, Universidad de Chile, Santiago, Chile; William J. Steinbach, Duke University Medical Center, Durham, NC; Elio Castagnola, Istituto Giannina Gaslini, Genova, Italy; Bonnie L. Davis, High Tor Limited, Nassau, Bahamas; Aditya H. Gaur, St Jude Children's Research Hospital, Memphis, TN; Wim J.E. Tissing, University Medical Center Groningen, University of Groningen, Groningen, the Netherlands; and Robert Phillips, Leeds Teaching Hospital, NHS Trust, Leeds; University of York, York, United Kingdom.

\section{Support}

Supported by meeting grants from the Canadian Institutes of Health Research and the Garron Comprehensive Cancer Centre. 


\section{AUTHORS' DISCLOSURES OF POTENTIAL CONFLICTS OF INTEREST}

Guideline for the Management of Fever and Neutropenia in Children With Cancer and Hematopoietic Stem-Cell Transplantation Recipients: 2017 Update

The following represents disclosure information provided by authors of this manuscript. All relationships are considered compensated. Relationships are self-held unless noted. I = Immediate Family Member, Inst = My Institution. Relationships may not relate to the subject matter of this manuscript. For more information about ASCO's conflict of interest policy, please refer to www.asco.org/rwc or ascopubs.org/jco/site/ifc.

Thomas Lehrnbecher

Consulting or Advisory Role: Gilead Sciences, Merck/Merck Sharp \& Dohme, Astellas Pharma

Speakers' Bureau: Astellas Pharma, Gilead Sciences

Research Funding: Gilead Sciences

Travel, Accommodations, Expenses: Astellas Pharma

Paula Robinson

No relationship to disclose

Brian Fisher

Research Funding: Pfizer (Inst), Merck (Inst), Ansun BioPharma (Inst)

Sarah Alexander

No relationship to disclose

Roland A. Ammann

Travel, Accommodations, Expenses: EUSA Pharma

Melissa Beauchemin

No relationship to disclose

Fabianne Carlesse

Speakers' Bureau: Astellas, United Medical, Pfizer

\section{Andreas H. Groll}

Consulting or Advisory Role: Astellas Pharma, Basilea, Gilead Sciences, Merck Sharp \& Dohme, Schering-Plough, Zeneus/Cephalon Speakers' Bureau: Astellas Pharma, Basilea, Gilead Sciences, Merck Sharp \& Dohme, Schering-Plough, Zeneus/Cephalon, Pfizer

Research Funding: Gilead Sciences, Merck Sharp \& Dohme, Pfizer, Schering-Plough

Gabrielle M. Haeusler

No relationship to disclose

\section{Maria Santolaya}

No relationship to disclose

William J. Steinbach

Consulting or Advisory Role: Gilead Sciences, Merck

Research Funding: Astellas Pharma

\section{Elio Castagnola}

Consulting or Advisory Role: Basilea, Astellas Pharma, Pharmaceutica, Gilead Sciences, Pfizer

Travel, Accommodations, Expenses: Pfizer

Bonnie L. Davis

No relationship to disclose

L. Lee Dupuis

Consulting or Advisory Role: Jazz Pharmaceuticals

Research Funding: Jazz Pharmaceuticals

Aditya H. Gaur

Research Funding: Gilead Sciences (Inst)

Wim J.E. Tissing

No relationship to disclose

Theo Zaoutis

Consulting or Advisory Role: Napriva

Research Funding: Merck (Inst)

Robert Phillips

No relationship to disclose

Lillian Sung

No relationship to disclose 
Lehrnbecher et al

\section{Acknowledgment}

We thank Sandra Cabral and Erin Plenert for administrative support. 